\title{
Climate and environmental changes in the Mt. Kenya region
}

\author{
Christine A. Omuombo
}

\begin{abstract}
Paleo records from Lake Nkunga show that climatic and environmental changes in this region were gradual and subtle during the last millennium. We highlight the importance of sedimentary records in providing a baseline for future conservation efforts on Mt. Kenya.
\end{abstract}

The last few hundred years have been characterized by increasing anthropogenic utilization of land and land-based resources, resulting in significant changes to the landscape and ecosystems, both in their structure and function. Baseline climate and land-use parameters can be deduced from climate-sensitive lakes with a high degree of reliability (Olago and Odada 2004). Forest cover, in particular, has seen unprecedented disturbances in recent times due to human occupation and modifications in land-use patterns. The overprint of anthropogenic influence on the climate signal is difficult to decipher without clear records of long-term change. Lake sediments within forests are ideal proxy archives to investigate the linkages between natural and anthropogenic factors. In the last millennium, evidence of climate and environmental change from decadal to centennial scales (Tierney et al. 2013; Verschuren et al. 2000) reveal floral and aquatic transformations that can be used as baselines for our decision-making regarding the conservation of our natural resources.

\section{Climate context and human impact during} the last millennium over East Africa

During the Late Holocene, East Africa experienced warm and moist conditions (Kiage and Liu 2006), punctuated by two key climatic events: The Medieval Climate Anomaly (MCA; 950-700 cal yr BP) and the Little Ice Age (LIA; 700-100 cal yr BP), observable in proxy records from many sites. The MCA was dry with low lake levels and was synchronous among various sites within a relatively narrow time window. In contrast, the timing of the LIA is highly variable, with the first phase of the LIA corresponding to maximum lake levels due to increased precipitation and the second phase displaying lake-level regressions punctuated by centennial- and decadal-scale droughts (Verschuren et al. 2000). These climatic events coincided with the expansion and settlement of various communities and are therefore difficult to isolate from anthropogenic impacts on the ecosystem responses.

The expansion of trade routes between the interior and the coast of East Africa in the 19th century played a key role in land-cover modification. The spread of domesticated crops from different parts of the world such as East Asia (banana, rice, and cassava) and South and Central America (maize, tomato, and avocado) have been archived in sedimentary records documenting population expansion in the region (Marchant et al. 2018). However, comprehensive datasets describing both the anthropogenic and climate influences on land use only exist for a handful of sites in East Africa, such as lakes Victoria and Naivasha in Kenya.

\section{The Mt. Kenya highlands} during the last millennium

Mt. Kenya Forest is a protected area in the East Africa highlands. Several crater and glacial lakes located in different ecological zones of the mountain have been studied to better understand the climatic and environmental signals within their sediments. One of the lakes within Mt. Kenya Forest, Sacred Lake (2350 $\mathrm{m}$ asl), hosts the longest records of climate and environmental change spanning the period from 115,000 cal yr BP to present (Olago 2001). During the 20th century the forested catchment areas were converted to agriculturally productive lands for commercial and subsistence farming. As a consequence, an explosion of the human population relying on the utilization of forest-based resources and overuse of arable and pasture lands is an increasing threat to the present-day forest ecosystem.

The first written records of human occupation of the Mt. Kenya region by local communities was about $200 \mathrm{cal}$ yr BP. The extent of their invasion into the montane forest region is not well known (Ndichu 2009); what has been established is that this expansion coincided with periods of conflict

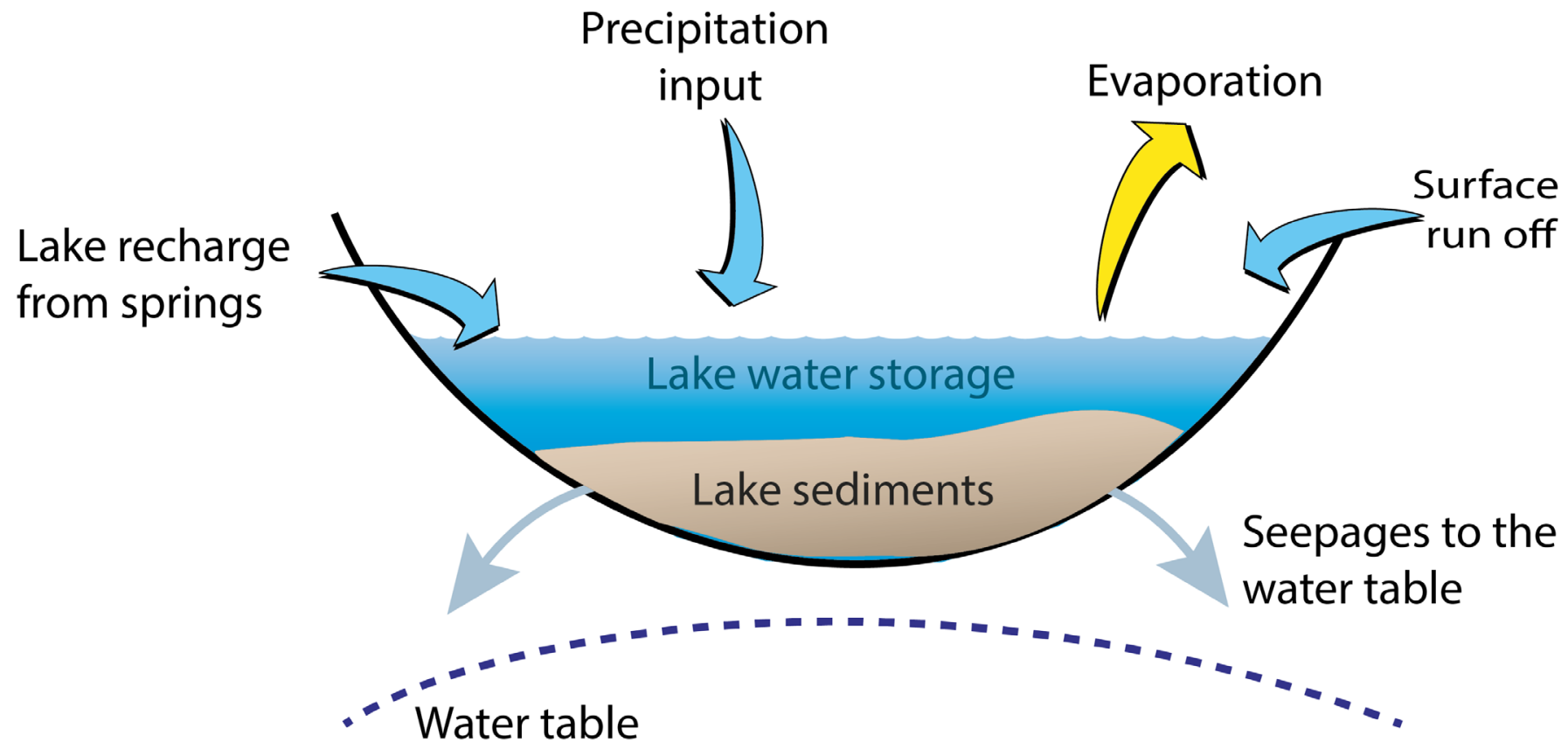

Figure 1: A simplified lake water budget model for Lake Nkunga. 
- Low lake levels

- Rejuvenating lake phase - Wetter conditions

- Coincides with MCA - Steady moisture balance

- Progressive shallowing of lake

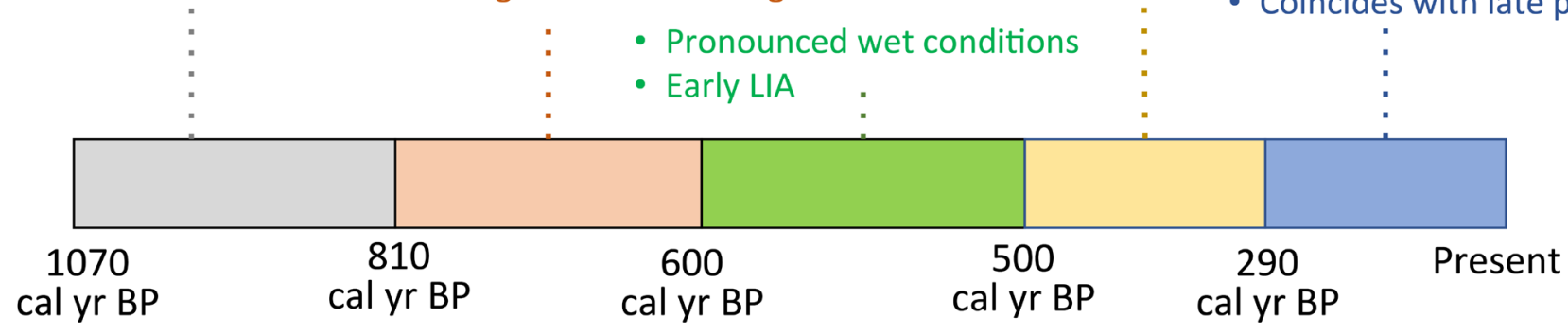

- Transition to drier conditions

- Establishment of modern lake

- Coincides with late phase LIA

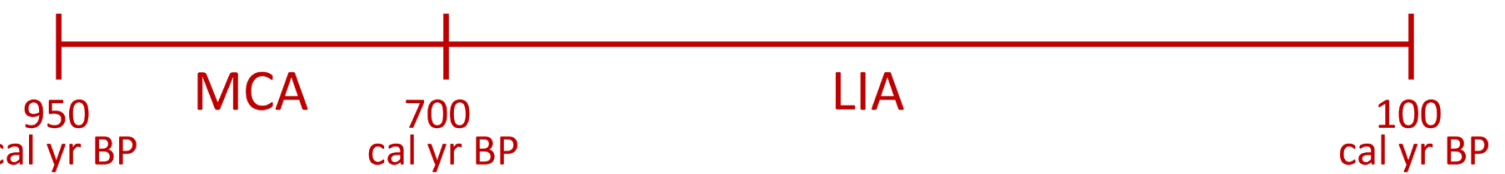

Figure 2: The interpretation of sedimentary archives from Lake Nkunga (sketch not to scale).

over natural resources and civil wars during decadal-scale droughts (Verschuren et al. 2000). Therefore, it is possible that the anthropogenic signal for the last two centuries from this region, detected through the presence of agricultural traces in the sedimentary record, may be overestimated, requiring further analysis to better understand the observed changes.

Lake Nkunga is one of the shallow crater lakes on the northeastern slopes of the mountain located at the equator at $1780 \mathrm{~m}$ asl and is located $10 \mathrm{~km}$ below Sacred Lake (Omuombo et al. 2020). Previous studies from this lake indicate that sedimentation resumed during the Late Holocene after a hiatus from 30,000-1350 cal yr BP (Olago et al. 2000). The lake has since persisted as a permanent water body archiving sediment over the last millennium. The lake exhibits swamp-like conditions due to its shallow depth (1.9 $\mathrm{m}$ on average) and is recharged by precipitation and springs emanating from fissures located at higher altitudes to the east and west and has no known outlet (Fig. 1). We examined a short 89-cm core from this lake and carried out various biogeochemical analyses (mineralogy, magnetic susceptibility, and organic and elemental geochemistry) to decipher the lake responses to climatic and environmental changes during the last millennium (Omuombo et al. 2020).

The hydrological record commences with a warm MCA that coincides with a lake rejuvenation phase and exhibits characteristics signifying a low lake level (Fig. 2). Post MCA a transition to wetter conditions within the first phase of the LIA is apparent between 600-500 cal yr BP (Fig. 2). Peak sediment influx and the development of swamp conditions (Omuombo et al. 2020) are observed during this time. A relatively stable lake level from 500-290 cal yr BP that has persisted to the present day shows subtle responses to drier conditions. Charcoal particles were visible in the sediments during this stable period, but the link to either anthropogenic or natural fires is yet to be resolved.

Anthropogenic influence in our sedimentary record cannot be excluded, even though the first documented human occupation of Mt. Kenya was shortly after this period (ca. 200 cal yr BP). The lake has not changed significantly since 290 cal yr BP, perhaps pointing to the vital role of groundwater recharge from springs located above the lake in stabilizing lake levels.

\section{The role of paleo information in conservation for Mt. Kenya}

Lake Nkunga lies at the border of the dry montane forest zone of Mt. Kenya and a human occupation area. It serves as a water source for the villages around it and the wildlife within the Mt. Kenya Forest ecosystem. Recently, concerns were voiced regarding the terrestrialization of the lake due to the presence of reeds and floating mats of water lilies, sedges, and ferns that have restricted access to lake water. While catchment erosion and weathering processes from anthropogenic activities play a significant role in sediment supply in lakes, our record shows that from 290 cal yr BP to present, the sedimentation rate has declined from $0.4 \mathrm{~cm} / \mathrm{yr}$ to a constant rate of $0.3 \mathrm{~cm} / \mathrm{yr}$. The current efforts to reclaim the lake include weed control and the establishment of an ecotourism site through the development of picnic areas, camping sites, and nature trails to increase community income.

Continued use and future development of Lake Nkunga's forested catchment need to be considered in the context of long-term lake-level changes and internal processes. The lack of a distinct anthropogenic signal from the Lake Nkunga record presents a baseline for the impact of future activities within the lake's catchment. Mt. Kenya Forest provides an important habitat for wildlife in the region, and thus conservation efforts are warranted. Our insights from the paleorecord of lake hydrology suggest that it is indeed important to conserve the forested catchment as a means to sustain the groundwater recharge to the springs that feed the lake. These springs play a critical role in managing the lake water budget (Fig. 1). The integration of paleo information into modern day management of natural resources is lacking despite the availability of such data from several additional sites in East Africa. Better informed governance and management of natural resources, especially during these unprecedented times of changing climatic and environmental conditions, is therefore possible. Consideration of past, present, and future changes could allow for the integration of catchment management policies critical for reaching sustainable development goals.

\section{ACKNOWLEDGEMENTS}

The author thanks D. Olago and D. Williamson for their helpful guidance and discussions. Support was provided by the TECLEA project, UMR METIS, UMR LOCEAN, and UMR CEREGE. Funding for this work was provided by IRD-DPF.

\section{AFFILIATION}

Department of Geology, University of Nairobi, Kenya CONTACT

Christine Omuombo: omuombo@uonbi.ac.ke

\section{REFERENCES}

Kiage LM, Liu KB (2006) Prog Phys Geogr 30(5): 633-658 Marchant R et al. (2018) Earth-Sci Rev 178: 322-378

Ndichu RW (2009) Drought and Flood Events and the Social-Economic and Political Impacts Experienced, 300-1900 AD. Sanctified Press, 384 $\mathrm{pp}$

Olago DO (2001) Clim Res 17: 105-121

Olago DO et al. (2000) J Afr Earth Sci 30: 957-969

Olago DO, Odada EO (2004) In: Battarbee RW et al. (Eds) Past Climate Variability through Europe and Africa: Palaeo-research in Africa: relevance to sustainable environmental management and significance for the future. Kluwer Academic Publishers, 551-565

Omuombo C et al. (2020) Sci Afr: e00416

Tierney JE et al. (2013) Nature 493: 389-392

Verschuren D et al. (2000) Nature 403: 410-414 